\title{
Neumonía organizada: fibroblastos intra-alveolares Medicina de precisión
}

\section{Organizing pneumonia: intra-alveolar fibroblasts Precision medicine}

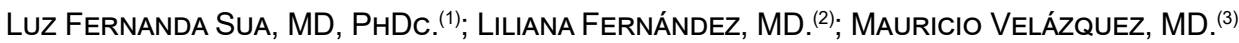

${ }^{(1)}$ Especialista en Anatomía Patológica y Patología Clínica. Departamento de Patología y Medicina de Laboratorio. Patología pulmonar. Ciencias Biomédicas. Grupo de investigación Biomédica en Tórax. Universidad ICESI. Fundación Valle del Lili. Cali, Colombia.

${ }^{(2)}$ Especialista en Medicina interna. Subespecilista en Neumología y Neumología intervencionista. Jefe del Servicio de Neumología. Grupo de Investigación Biomédica en Tórax. Universidad ICESI. Fundación Valle del Lili, Cali, Colombia.

${ }^{(3)}$ Especialista en Cirugía General. Subespecialista en Cirugía de Tórax. Servicio de Cirugía de Tórax. Grupo de investigación Biomédica en Tórax. Universidad ICESI. Fundación Valle del Lili. Cali, Colombia. Correspondencia: Luz Fernanda Sua, correo electrónico: lfsua@fcvl.org

Recibido: 15/11/14, Aceptado: 10/12/14

\section{Introducción}

La American Thoracic Society/European Respiratory Society (ATS/ERS) en su consenso sobre la clasificación de las neumonías intersticiales de 2002 (1), define distintas entidades clinicopatológicas (tabla 1) con base en la clínica, imágenes radiológicas y criterios histológicos. En este artículo se hace énfasis en el manejo multidisciplinario para el diagnóstico de patologías pulmonares, que se traduce en medicina de precisión (2).

\section{Definición}

Entidad clínico-patológica caracterizada por nódulos polipoides de tejido de granulación suelto dentro de los espacios aéreos.

\section{Etiología}

Idiopática, infección (bacterias, hongos, virus y parásitos), medicamentos (amiodarona, bleomicina, busulfán, sales de oro, sulfasalazina, tacrolimus y cocaína), enfer- medades del tejido conectivo (artritis reumatoide, dermatomiositis, síndrome de Sjögren, polimialgia reumática), trasplante (pulmón, médula ósea, hígado), enfermedad inflamatoria intestinal (colitis ulcerativa, enfermedad de Crohn), desórdenes hematológicos (síndrome mielodisplásico, leucemia), desórdenes inmunológicos/inflamatorios (enfermedad de Behçet, inmunodeficiencia común variable) y radioterapia $(3,4)$.

\section{Tipos de biopsias}

- Transbronquial: En nuestra experiencia realizamos un mínimo de cinco y un máximo de diez fragmentos, en los cuales se deben observar fibroblastos intraalveolares al menos en un foco, suficiente para el diagnóstico de la entidad dentro del contexto clínico radiológico (figura 1).

- Cuña pulmonar: Ha sido el espécimen de elección en entida-

Tabla 1. ATS/ERS clasificación de patrones histológicos y contraparte clinicopatológica

\begin{tabular}{|l|l|}
\hline Patrón histológico & Diagnóstico clinicopatológico \\
Neumonía organizada & Neumonía organizada criptogénica \\
\hline
\end{tabular}




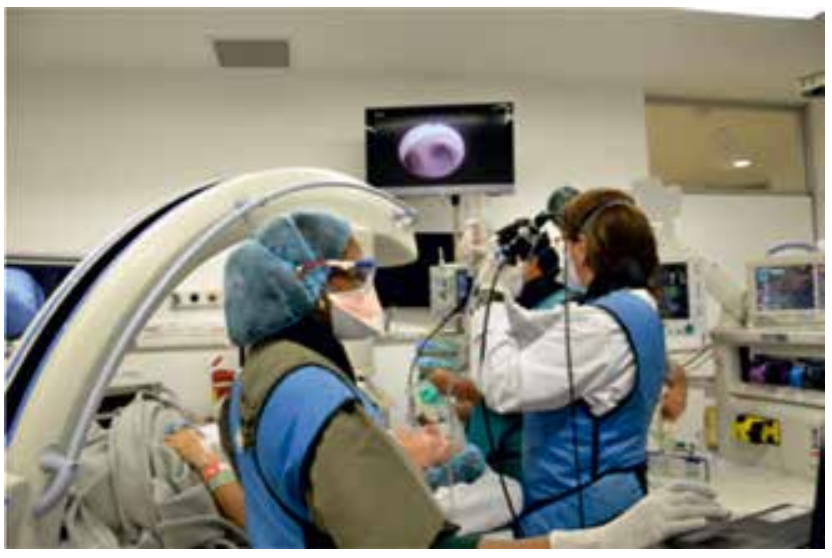

Figura 1. La biopsia transbronquial es útil para el diagnóstico histopatológico cuando es posible correlacionar el cuadro clínico y radiológico del paciente.

des en las que se requiere observar patrones histológicos complejos.

\section{Lavado bronco-alveolar}

Es útil para proporcionar información sobre diagnósticos diferenciales.

\section{Descripción macroscópica}

No existen cambios macroscópicos que permitan determinar un diagnóstico desde la pieza quirúrgica; usualmente el área del parénquima comprometido suele ser de color pardo claro, con cambio en la densidad del tejido pulmonar a la palpación (figura 2).

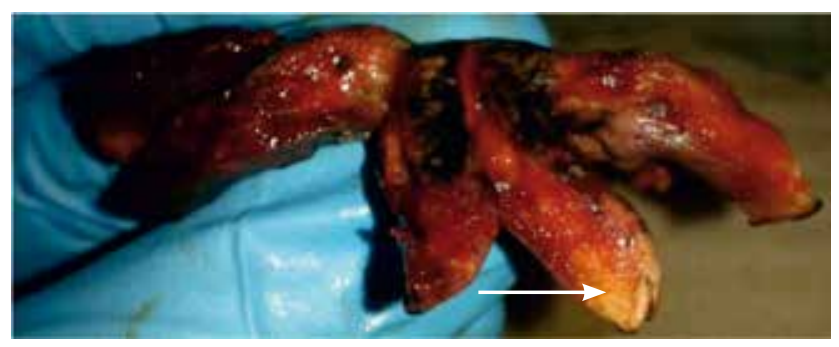

Figura 2. En el estudio macroscópico los cambios del parénquima suelen observarse de color pardo claro y palparse mas consistente el área afectada.

\section{Descripción microscópica}

Se observan nódulos con fibroblastos formando tejido de granulación que se extienden a través de los poros de Kohn al siguiente alvéolo; se conoce como "Butterfly patron". La arquitectura pulmonar se muestra preservada, sin fibrosis, y el infiltrado inflamatorio intersticial acompañante es de tipo mononuclear (figuras 3 y 4).

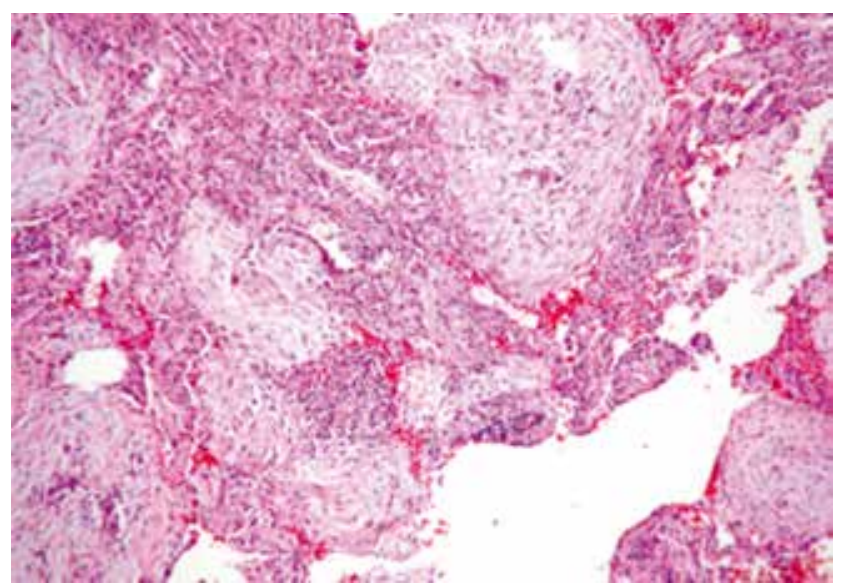

Figura 3. Coloración de hematoxilina y eosina. Presencia de fibroblastos intra-alveolares con formaciones nodulares polipoides de tejido de granulación.

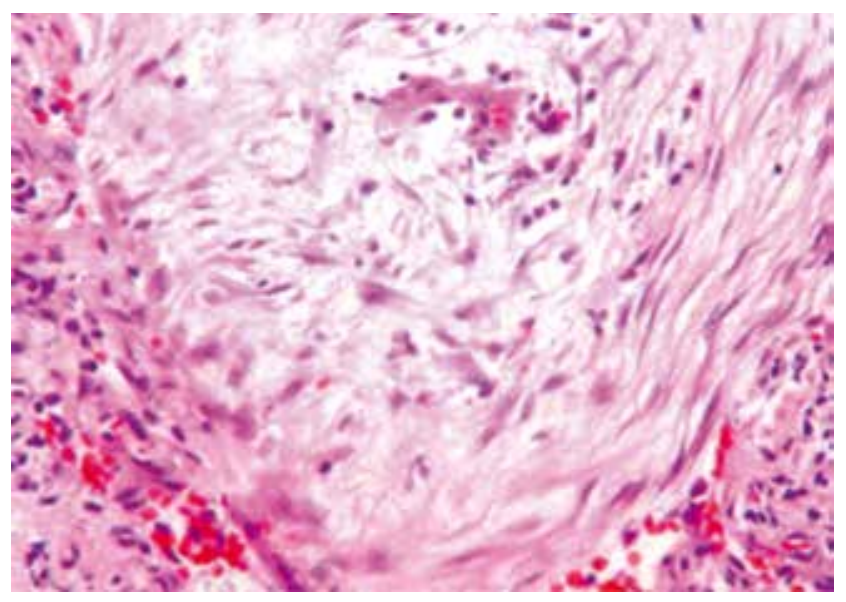

Figura 4. Coloración de hematoxilina y eosina. Presencia de fibroblastos intra-alveolares, con infiltrado inflamatorio mononuclear. 


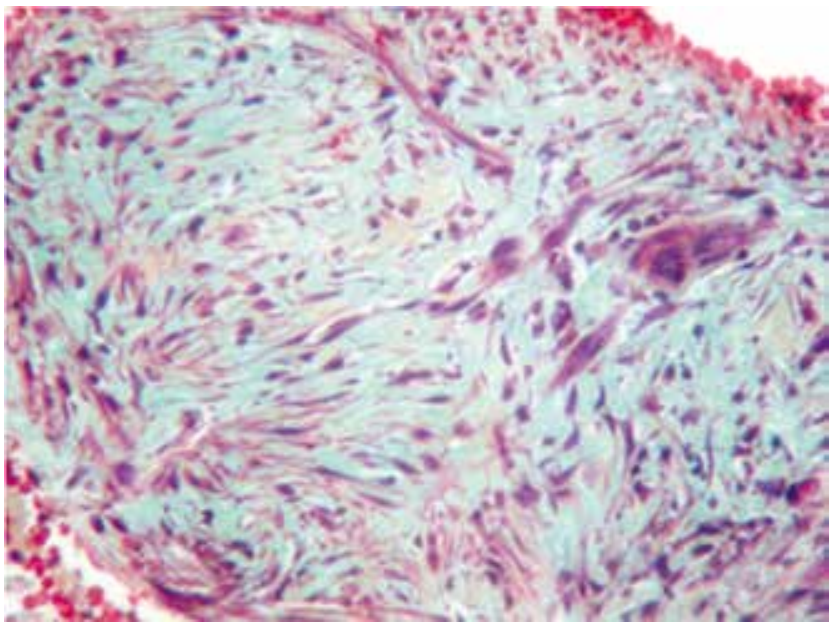

Figura 5. Coloración de Movat. En color verde se observa la producción de proteoglicanos de aspecto mucinoso por los fibroblastos jóvenes intra-alveolares.

\section{Coloración histoquímica}

Para estudiar la localización de los fibroblastos en el parénquima pulmonar y determinar su estadio celular, utilizamos la coloración de Movat, un pentacrómico que permite identificar colágeno, tejido muscular, fibras reticulares, mucina y fibrina (figuras 5 y 6 ).

\section{Puntos clave}

- En el análisis de la biopsia es importante conocer si el paciente recibe corticosteroides, puesto que el tratamiento altera el estadio histopatológico de la enfermedad.

- La neumonía organizada es un diagnóstico de exclusión y la interpretación de la biopsia pulmonar requiere una correlación clínica y radiológica. Por tanto, con el trabajo multidisciplinario se logra llegar a consensos diagnósticos que se traducen en medicina de precisión.

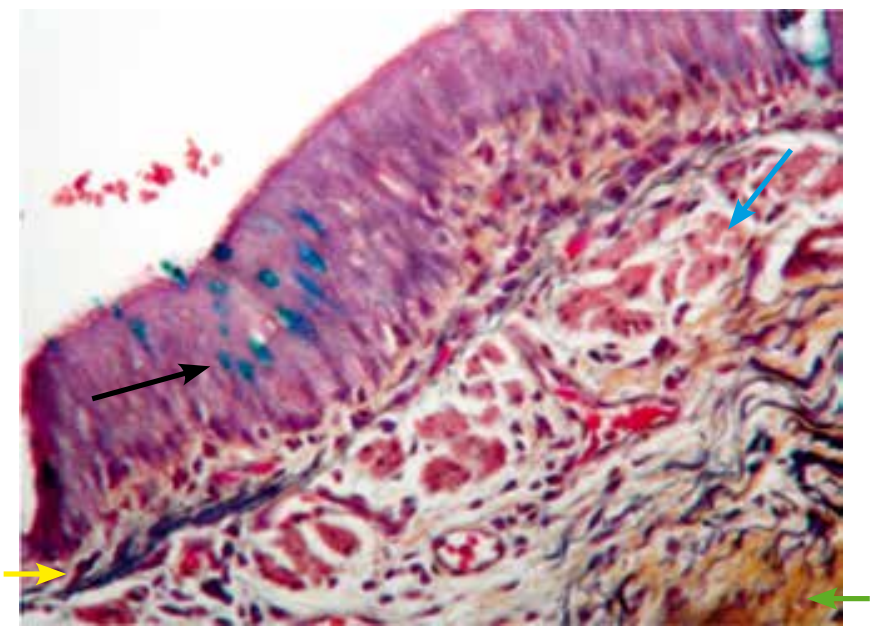

Figura 6. Coloración de Movat. Pared bronquial. Se observan fibras elásticas (flecha amarilla), colágeno (flecha verde), mùsculo músculo (flecha azul) y células productoras de mucina en el epitelio bronquial (flecha negra).

\section{Conflictos de intereses}

Los autores declaran no tener conflictos de interés.

\section{Bibliografía}

1. American Thoracic Society/European Respiratory Society. International Multidisciplinary consensus classification of the idiopathic interstitial pneumonias. Am J Respir Crit Care Med. 2002;165:277-304.

2. Flaherty KR, King TE Jr, Raghu G, et al. Idiopathic interstitial pneumonia: what is the effect a multidisciplinary approach to diagnosis? Am J Respir Crit Care Med. 2004; 170:904-10.

3. Ergin AB, Fong N, Daw HA. Rituximab-induced bronchiolitis obliterans organizing pneumonia. Case Rep Med. 2012;2012:680431.

4. Filippone EJ, Carson JM, Beckford RA, Jaffe BC, Newman E, Awsare BK, et al. Sirolimus-induced pneumonitis complicated by pentamidine-induced phospholipidosis in a renal transplant recipient: a case report. Transplant Proc. 2011;43:2792-7. 